\title{
The KDR (VEGFR-2) Genetic Polymorphism Q472H and c-KIT Polymorphism M541L Are Associated With More Aggressive Behaviour in Astrocytic Gliomas
}

\author{
NIYAZ ZAMAN $^{1}$, SERENA SANTHANA DASS ${ }^{1}$, PERSEPHONE DU PARCQ ${ }^{2}$, SUZANNE MACMAHON ${ }^{3}$, \\ LEWIS GALLAGHER $^{3}$, LISA THOMPSON ${ }^{3}$, JAMSHID S. KHORASHAD ${ }^{4}$ and CLARA LIMBÄCK-STANIC ${ }^{1,2}$ \\ ${ }^{I}$ Division of Brain Sciences, Department of Medicine, Imperial College London, London, U.K.; \\ ${ }^{2}$ Department of Cell Pathology, Imperial College Healthcare NHS Trust, London, U.K.; \\ ${ }^{3}$ Clinical Genomics, The Centre for Molecular Pathology, \\ The Royal Marsden NHS Foundation Trust, London, U.K.; \\ ${ }^{4}$ Department of Immunology and Inflammation, Imperial College London, London, U.K.
}

\begin{abstract}
Background/Aim: Better diagnostic and prognostic markers are required for a more accurate diagnosis and an earlier detection of glioma progression and for suggesting better treatment strategies. This retrospective study aimed to identify actionable gene variants to define potential markers of clinical significance. Materials and Methods: 56 glioblastomas (GBM) and 44 grade 2-3 astrocytomas were profiled with next generation sequencing (NGS) as part of routine diagnostic workup and bioinformatics analysis was used for the identification of variants. CD34 immunohistochemistry (IHC) was used to measure microvessel density (MVD) and Log-rank test to compare survival and progression in the presence or absence of these variants. Results: Bioinformatic analysis highlighted frequently occurring variants in genes involved in angiogenesis regulation (KDR, KIT, TP53 and PIK3CA), with the most common ones being KDR (rs1870377) and KIT (rs3822214). The KDR variant was associated with increased $M V D$ and shorter survival in GBM. We did not observe any correlation between the KIT variant and MVD; however, there was an association with tumour grade. Conclusion: This study highlights the role of single-nucleotide variants (SNVs) that may be considered non-pathogenic and suggests the prognostic
\end{abstract}

This article is freely accessible online.

Correspondence to: Clara Limbäck-Stanic, Department of Cell Pathology, Imperial College Healthcare NHS Trust, Charing Cross Hospital, Fulham Palace Road, London, W6 8RF, United Kingdom. Tel: +44 02033110411, Fax: +44 0203311364, e-mail: climback@ic.ac.uk

Key Words: Glioma, microvascular proliferation, KIT, KDR, artificial intelligence, polymorphism, next-generation sequencing. significance for survival of KIT rs3822214 and KDR rs 1870377 and potential importance in planning new treatment strategies for gliomas.

Diffuse gliomas are the most frequent primary malignant tumours of the central nervous system (CNS) in adults, with an annual incidence of approximately 5/100,000 per year (1). The majority consists of astrocytic tumours, which include more differentiated and slower-growing diffuse astrocytomas, isocitrate dehydrogenase (IDH) mutant (mut) (WHO grade 2) and high-grade astrocytomas, IDH mut (WHO grade 3 and 4), IDH wildtype (WT) GBM (WHO grade 4), and other genetically defined but rare subtypes $(2,3)$. IDH WT GBM is the most aggressive and most common type of glioma in adults, corresponding to $50 \%$ of all primary CNS malignancies (2). Lower grade (grades 2 and 3) IDH mut astrocytomas follow a natural progression to grade $4 \mathrm{IDH}$ mut astrocytomas, or secondary GBM (2). GBM is characterised by strong resistance to chemotherapy $(4,5)$ and radiotherapy (6), whilst the often-precarious location and infiltrating growth of the tumour results in largely ineffective surgical removal. All these factors contribute to the dismal prognosis of grade 4 gliomas with a 5 -year survival of $5 \%$ (7). The current diagnosis of gliomas relies on magnetic resonance imaging, histological assessment of tumour tissue $(8,9)$ and genetic profiling of tumour cells $(2,10)$. The histological hallmarks of GBM in comparison to lower grade astrocytomas are: i) high proliferation activity and ii) microvascular proliferation with or without necrosis $(2,11)$. GBM is known as one of the most highly angiogenic tumours and the extensive vascular network is associated with an elevated presence of pro-angiogenic factors released by the tumour cells (12-14). The genetic profile of gliomas is assessed using a combination of techniques, such as IHC, 
sequencing and copy number variation $(\mathrm{CNV})$ studies. An epigenetic marker, methylguanine-DNA-methyltransferase (MGMT) promoter methylation is also routinely assessed as a crucial predictive parameter for patients' management (15). NGS is increasingly used to assess the presence of mutations in relevant genes $(16,17)$ as it offers a rapid and comprehensive molecular analysis. Using NGS, the mutation status of only a subset of panel genes is routinely considered for diagnostic work-up. Hence, the diagnostic and prognostic significance of the mutation status in many of the other oncogenes in the sequencing panels is not fully characterised in the context of glioma.

In this study, we investigated the correlation between these non-routinely assessed oncogenes from a panel of 50 genes together with clinical, morphological and molecular features of patients with diffuse gliomas, so as to isolate gene variants, which might hold a diagnostic or prognostic significance as well as potential relevance for treatment. We analysed tumour tissues from 100 patients diagnosed with diffuse astrocytic glioma ranging from WHO grade 2 to grade 4 and identified frequent and potentially actionable SNVs in genes, KDR and KIT. The KDR variant rs 1870377 in particular, has also been reported in other malignancies and has been variably associated with angiogenesis modulation and shorter survival (18-22). In this study, we explored the role of these $K D R$ and $K I T$ variants as well as TP53 mutations in vascular proliferation and aggressiveness in diffuse gliomas.

\section{Materials and Methods}

Patients and tumour samples. For this study, a total of 100 cases were assessed. These included biopsies and resected tumour samples of patients who were operated on at Imperial College Healthcare NHS Trust, London, from 2016 to 2019. The histological and integrated molecular diagnoses were established according to the 2016 WHO Classification of CNS tumours and cIMPACT guidelines using standard protocols of the Department of Cell Pathology of Imperial College $(2,3)$. Additionally, the $M G M T$ promoter methylation status was assessed in all GBM cases by methylation - sensitive high-resolution melting analysis at the Department of Neuropathology of the Institute of Neurology, University College London. We identified $4 \mathrm{IDH}$ mut GBM and these were excluded from MVD and survival analyses as mut $I D H$ significantly influences prognosis in GBM (23). Patient samples from 2016-2017 did not have NGS analysis as the routine genetic profile was obtained using Sanger sequencing coupled with PCR and qPCR to identify variants of interest. In these cases, SNVs of interest were assessed as follows (see genotyping). Follow-up data were obtained from clinical databases. The survival time was defined as the time from the first surgery to the date of death or last contact. Time to progression was defined as the time between initial diagnosis and progression on neuroimaging. The data was provided from samples used for diagnostic purposes and were de-identified to the researchers.
Sequencing. Samples from 2018 were sequenced using the IonTorrent S5 sequencer (ThermoFisher Scientific, Waltham, MA, USA) and cases from 2019 were profiled using MiSeq instrument (Illumina, San Diego, CA, USA). IonTorrent sequencing was performed at the Molecular Pathology Laboratory of Imperial College using the Ion AmpliSeq ${ }^{\mathrm{TM}}$ Cancer Hotspot Panel v2 (ThermoFisher Scientific, Catalogue no. 4475346), according to manufacturer's instruction. Illumina sequencing was performed at the clinical genomics lab of the Royal Marsden Hospital, London, using a QIAseq (Qiagen, Hilden, Germany) targeted DNA from a panel of 33 genes developed in-house according to manufacturer's instructions; see Table II for sequencing panel details.

NGS data analysis. NGS generated by IonTorrent sequencing is subject to in-house quality control parameters using IonReporter whilst NGS data generated by Illumina sequencing underwent quality control at the clinical genomics lab of the Royal Marsden Hospital. Unfiltered NGS reports were collected and a looser cutoff frequency of $0.1 \%$ was applied. COSMIC (24), PolyPhen (25), CKB BOOST (26) and OncoKB (27) were used to probe known and unknown variants of genes in the panel as well as the significance of the variant itself. The softwares Bioconductor (28), FactoMineR (29) and RStudio were used for all subsequent bioinformatic analysis.

Genotyping. Cases that had not received NGS or sequencing information was unavailable were genotyped for KDR and KIT with restriction enzyme digestion and qPCR respectively. The following primers were used to amplify the segment of DNA containing the KDR variant (rs18170377): KDR-F: 5'-GGAAGTCCTCCACACTTCTCC3' and KDR-R: 5'-GGTAGGCTGCGTTGGAAGTTA-3'. Touchdown PCR from $65^{\circ} \mathrm{C}$ to $55^{\circ} \mathrm{C}$ was used to amplify the region of interest. PCR products were visualised using QIAXcel (Qiagen). PCR products were digested with AluI (New England Biolabs, Ipswich, MA, USA) at $37^{\circ} \mathrm{C}$ for $1 \mathrm{~h}$. AluI specifically digests variant KDR (rs1870377). Digested PCR products were visualised using QIAXcel Advanced system (Qiagen). TaqMan ${ }^{\mathrm{TM}}$ SNP genotyping qPCR assay (ThermoFisher Scientific) was performed according to manufacturer's instructions using a QuantStudio 5 Real-Time PCR System (ThermoFisher Scientific) to detect KIT variant (rs3822214).

Artificial neural network (ANN). ANN were constructed using Python 3.7, TensorFlow 2.0 (30) and the functional Keras API (31) using the complete targeted NGS data of 48 GBMs. To predict MGMT promoter methylation we approached it as a binary classification problem where 0 and 1 represent the unmethylated and methylated states, respectively. Our ANN consists of a 34-node input layer sequentially followed by 3 hidden layers containing 17, 9 and 5 nodes, with ReLU activations and a final single node output layer with a sigmoidal activation. Drop-out layers with a value of 0.2 were included in-between each hidden layer to prevent overfitting. NGS data were augmented by rearranging the order of gene mutation and variant frequencies for each patient. Processed NGS data were split into an 80:20, training and testing dataset. The model was compiled with a binary cross-entropy loss function and an Adaptive Moment Estimation optimizer with a learning rate of 0.025 . The number of nodes for each hidden layer and the number of hidden layers were determined through a series of optimisations and were used to design a feed-forward neural network. We systematically removed the mutation information of genes and 
Table I. Overview of glioblastomas and grade 2-3 glioma populations. Data are segregated by gender as well as overall cohort statistics, including the proportion of male to female patients, mean age $\pm S E M$ in years as well as the pathogenic mutation frequency of TP53, and PIK3CA (if known), IDH1/2 and the presence of KDR Q472H and KIT M541L.

\begin{tabular}{lccc}
\hline Glioblastoma $\mathrm{n}=56$ & Male & Female & Cohort \\
\hline Proportion & $68 \%$ & $32 \%$ & \\
Age (Years) & $60.1 \pm 2.03$ & $61.5 \pm 2.57$ & $60.54 \pm 1.56$ \\
TP53 & $32 \%$ & $33 \%$ & $32 \%$ \\
PIK3CA & $26 \%$ & $22 \%$ & $25 \%$ \\
IDH1/2 & $11 \%$ & $0 \%$ & $7 \%$ \\
KDR Q472H & $42 \%$ & $56 \%$ & $46 \%$ \\
KIT M541L & $28 \%$ & $39 \%$ & $14 \%$ \\
& & & \\
Low grade glioma n=44 & Male & Female & Cohort \\
\hline Proportion & $67 \%$ & $33 \%$ & \\
Age (Years) & $36.37 \pm 1.79$ & $35.27 \pm 2.31$ & $36 \pm 1.41$ \\
TP53 & $37 \%$ & $27 \%$ & $33 \%$ \\
PIK3CA & $7 \%$ & $20 \%$ & $11 \%$ \\
IDH1/2 & $83 \%$ & $93 \%$ & $87 \%$ \\
KDR Q472H & $33 \%$ & $73 \%$ & $47 \%$ \\
KIT M541L & $17 \%$ & $33 \%$ & $22 \%$ \\
\hline
\end{tabular}

measured whether the accuracy of the ANN changes in response to this and determined whether the model begins to overfit upon losing these data, by comparing loss values.

Immunohistochemistry. Formalin-fixed paraffin-embedded sections were stained using a ready-to-use CD34 antibody (Leica Biosystems, Newcastle upon Tyne, UK) using a Leica BOND autostainer and was visualised using a BOND Polymer Refine Detection kit (Leica Biosystems). For each biopsy, the three tumour areas showing the highest MVD were selected and the number of blood vessels was counted at $20 \times$ magnification, as previously described $(32,33)$. Biopsies in which the tumour area was small $(<1$ $\mathrm{cm}^{2}$ ) were excluded from the analysis.

Statistical analysis. Statistical analysis was carried out using R, version 4.0.0 and graphics were generated using the Bioconductor (28) and FactoMineR (29) packages in RStudio and Graph Pad Prism 7. We used one-way ANOVA and unpaired $t$-tests to determine the significance of gene variants on MVD and Log-rank test for survival analysis. Fisher's exact test was used to determine whether gene variants influences MGMT promoter methylation. $\mathrm{X}^{2}$ test was used to assess the distribution of variants across tumour grades.

\section{Results}

A total of 100 cases were included in this study. There were 52 IDH WT GBMs, the aforementioned $4 \mathrm{IDH}$ mut GBMs, and 44 lower grade (26 grade 2 and 18 grade 3) $I D H$ mut astrocytomas. Following exclusion due to suboptimal DNA quality and availability of NGS data, 48 GBM and 26 samples of grade 2 and 3 astrocytomas were qualified for generating a
Table II. Sequencing panels employed. CHPv2 panel was used to sequence glioblastoma cases prior to November 2018 while the Illumina panel is used after this date. Grade 2-3 gliomas were all sequenced using the CHPv2 panel.

\begin{tabular}{llllll}
\hline \multicolumn{2}{l}{ Cancer hotspot panel v2 (CHPv2) } & & & \\
\hline ABL1 & CTNNB1 & FLT3 & KDR & PDGFRA & SRC \\
AKT1 & EGFR & GNA11 & KIT & PIK3CA & STK11 \\
ALK & ERBB2 & GNAQ & KRAS & PTEN & TP53 \\
APC & ERBB4 & HNF1A & MET & PTPN11 & VHL \\
ATM & EZH2 & HRAS & MLH1 & RB1 & \\
BRAF & FBXW7 & IDH1 & MPL & RET & \\
CDH1 & FGFR1 & IDH2 & NOTCH1 & SMAD4 & \\
CDKN2A & FGFR2 & JAK2 & NPM1 & SMARCB1 & \\
CSF1R & FGFR3 & JAK3 & NRAS & SMO & \\
\hline
\end{tabular}

Illumina panel

\begin{tabular}{lllllll}
\hline AKT1 & CDKN2B & ERBB3 & GNAQ & KIT & NRAS & RUNX1 \\
ALK & CEBPA & ESR1 & HRAS & KRAS & PDGFRA & TERT \\
BRAF & CTNNB1 & FLT3 & IDH1 & MET & PIK3CA & TP53 \\
CALR & EGFR & FOXL2 & IDH2 & MPL & RAF1 & \\
CDKN2A & ERBB2 & GNA11 & JAK2 & NPM1 & RET & \\
\hline
\end{tabular}

mutation landscape. Disparities in the number of cases for further analyses were due to the availability of information for certain criteria (e.g. TP53 mutation status). Table I provides an overview of the patients included in the study.

Glioma mutation landscape. The mutation landscape was produced using archived data from NGS of 2018 and 2019 glioma cases. There was a correlation between age and mutation burden, which is expected given the accumulation of mutations over time (34) (Figures 1A and B). KDR (50\%), TP53 (47.9\%), KIT (43.75\%), EGFR (43.75\%) and PIK3CA $(31.25 \%)$ were the most frequently mutated genes in both GBM and grade 2-3 glioma groups (Figures $1 \mathrm{~A}$ and B). All patients with the $K D R$ variants carry the $\mathrm{Q} 472 \mathrm{H}$ variant (rs1870377) and those with the KIT variants carry the M541L variant (rs3822214). Gender and MGMT promoter methylation appear to have no discernible impact on the mutations and vice versa.

Relationship between KDR Q472H and PIK3CA/KIT mutations. The associations described by the Manhattan clustering of gene mutations in Figure 1A can be clearly visualised through the performing Principle Component Analysis (PCA) (Figure 2). We opted to use Manhattan clustering as it is less influenced by outlier data (35). TP53, $K D R, P I K 3 C A$ and KIT contribute most to the variance in mutation status between patients; all other genes are clustered towards the centre and have very little contribution, 


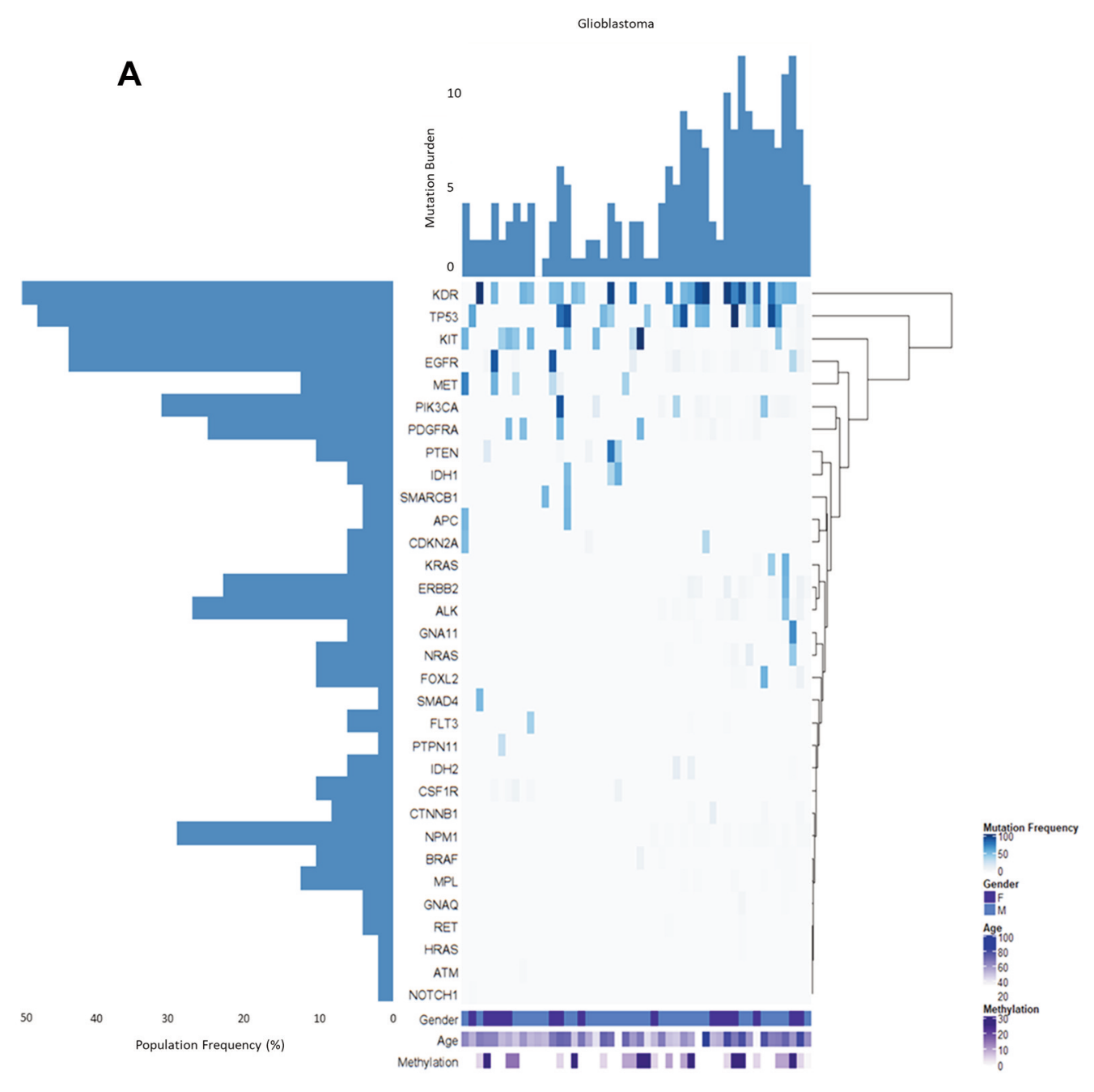

Figure 1. Continued

if any, to the variance between patients. The co-occurrence of PIK3CA and KIT is shown by their effect in the same direction in both principal components, while the effect of $K D R$ in the opposite direction of both components, relative to PIK3CA and KIT, suggests that mutations in KDR tend not to co-occur with $P I K 3 C A$ and $K I T$. This does not completely rule out the possibility of co-mutating, as seen in Figure 1A, albeit with low mutation frequencies $(<5 \%)$ of $P I K 3 C A$.

KDR Q472H increases MVD in GBMs, and is associated with shorter survival. $K D R$ is also referred to as vascular endothelial growth factor receptor 2 and has a defined role in promoting angiogenesis in both normal and cancer contexts, including gliomas $(36,37)$. We investigated whether the $\mathrm{Q} 472 \mathrm{H}$ variant of $K D R$ would affect angiogenesis by measuring MVD using IHC for the endothelial marker CD34 (Figure 3A and B). As expected, MVD was increased with tumour grade. The mean MVD for GBM, grade 3 and grade 2 astrocytoma were $191.1,120.3$ and 76.1 , respectively (Figure 3C). In our grade 2-3 population, we did not find a significant difference in MVD in patients with KDR and KIT variants (Figures 3D and F) and, accordingly, we did not find any significant impact on the time to progression in patients harbouring these variants (Figures $3 \mathrm{G}$ and I). We observed a $67 \%$ increase in MVD only in patients with grade 3 astrocytomas and pathogenic TP53 variants (Figure 3E) though this does not appear to affect overall survival (Figure $3 \mathrm{H})$. Conversely, in our GBM population, we found that $K D R$ Q472H increased MVD by 35\% (Figure 3J) and significantly reduced the probability of overall survival (Figure $3 \mathrm{~L}$ ); with Fisher's exact test, we found that this is not influenced by MGMT promoter methylation. KIT M541L had no impact on either parameter (Figure $3 \mathrm{~K}$ and $\mathrm{M}$ ). Enhanced angiogenesis in tumours is associated with irregular patterns of blood vessel 


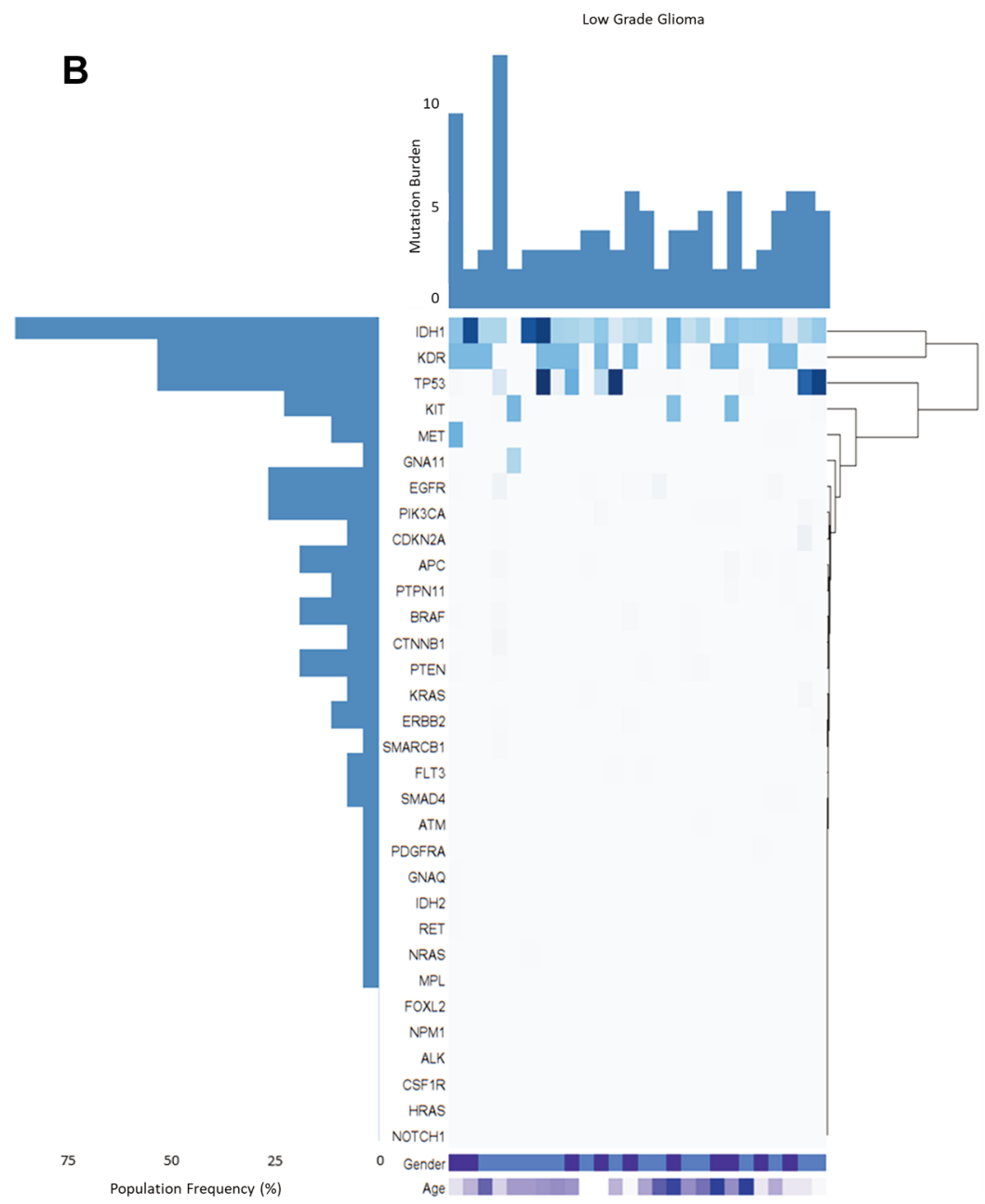

Figure 1. Heatmap of mutated genes for each (A) glioblastoma patient $(n=48)$ and (B) grade 2-3 glioma patient $(n=26$. The intensity of colour reflects the mutation frequency of that gene in a given patient, as well as the gender, age and MGMT promoter methlyation status for each patient. Mutation burden represents the number of mutations per patient. Population frequency is defined as the frequency of mutation in a given gene within the patient population, represented as a percentage. Legend is shown in the centre.

formation (38). Two patterns of microvascular proliferation can be recognised, a classical one showing endothelial multilayering and a bizarre one with formation of highly atypical glomeruloid vascular structures $(39,40)$. We did not observe any significant changes in the frequency of bizarre $v s$. classical angiogenesis in relation to tumour grade, pathogenic TP53/PIK3CA or KDR Q472H and KIT M541L status.

Increased frequency of KIT M541L in grade 3 and 4 glioma. KIT M541L appears to have no significant association with survival in GBM or grade 2-3 astrocytoma patient populations (Figures 3F, I, K, and M), we observed a clear and significant shift in the frequency of the KIT M541L variant in our lower grade glioma group. Only $8 \%$ of our grade 2 patients were positive for KIT M541L vs. 44\% of grade 3 and 26\% GBM patients, as shown in Figure 4.

Mutation status of angiogenesis-related genes predict MGMT promoter methylation status. We next wanted to investigate whether the SNV detected with the NGS panel could be used for predictive measures. To this end, we first sought to use the sequencing information to predict the methylation status of the MGMT promoter. We constructed an ANN using the targeted NGS data of all 48 GBM cases which received NGS. Our ANN could predict the MGMT methylation status of a patient with $86 \%$ accuracy using sequencing information from NGS, after the model iterated over the data 14 times (Figure 5A). The model did not perform overfitting in any case as the loss values 


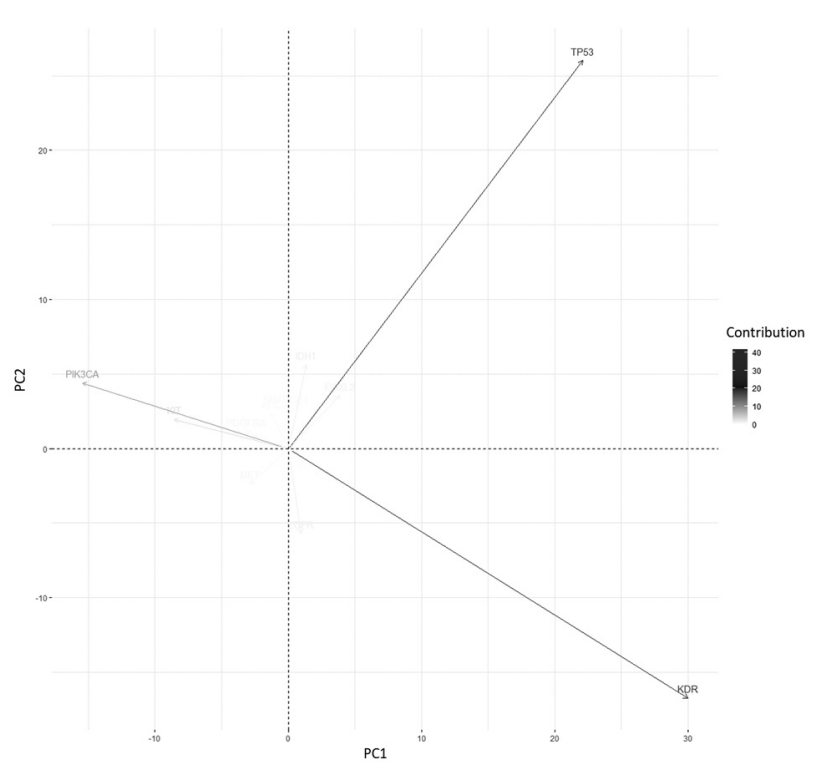

Figure 2. Principle component analysis of mutated genes in the glioblastoma patient population $(n=48)$. Genes are coloured according to their importance in distinguishing patients from one another. The direction in which the data are plotted relies on the effect of a feature in any given direction; genes aligned together are considered to be cooccurring, while genes in opposite directions are considered to generally occur in the absence of each other.

between training and test sets converged by the end of the training (Figure 5B). Next, we sought to investigate what information was necessary for the model to be able to accurately predict $M G M T$ methylation status. We found that the removal of $P I K 3 C A, K I T$ and $K D R$ has the most significant reduction in accuracy, reducing it to $16 \%$ from $86 \%$ (Figure $5 \mathrm{C}$ ) and resulted in overfitting (Figure 5J). Removal of solely $P I K 3 C A$ did not affect accuracy suggesting insignificance, while removal of KIT or KDR reduced the accuracy to $72 \%$ and $57 \%$, respectively (Figures 5D-F). Removing the mutation status of PIK3CA/KIT and PIK3CA/KDR reduced accuracy to 57\% and $72 \%$, respectively (Figures $5 \mathrm{G}$ and I). Reductions in model accuracy were not observed when removing the mutation status of the 31 other genes presented in Figure 1A. These findings suggest there is some level of correlation between PIK3CA, $K I T, K D R$ and $M G M T$ promoter methylation, previously unseen without deep learning techniques.

\section{Discussion}

This study set out to elucidate the importance and possible significance of non-routinely assessed oncogenes in the context of glioma. We found that the most frequent variants occurred in genes that are known to be involved in angiogenesis regulation: KDR, KIT, PIK3CA and TP53 (36, 37, 41-44). This clustering, as well as the heatmap, also suggested a redundant relationship between mutations in angiogenesis genes, KDR and $K I T$ (45) in the GBM cohort, wherein $K D R$ variants were predominantly present in the absence of KIT mutations or in low frequency of a KIT mutation.

Further inspection of the NGS data showed that all variants of $K D R$ detected were of the $\mathrm{Q} 472 \mathrm{H}$ variant while the KIT variants were KIT M541L. KDR Q472H is already known to be a germline variant $(18,46)$, and we observed it in $50 \%$ of our GBM group and $47 \%$ of grade $2-3$ astrocytomas, greater than the $21 \%$ of individuals reported positive in the general population (47). Our cohort was too small for population analysis. In addition, we did not have a matching non-tumour cohort available to determine whether KIT M541L is a germline variant, given the high frequency it presented $(43.75 \%)$.

VEGF signalling is central to tumour angiogenesis and its regulation is complex $(48,49)$. The $K D R \mathrm{Q} 472 \mathrm{H}$ variant is regarded as non-pathogenic but has been previously shown to increase MVD in melanoma (18) and lung (19) cancer and to be associated with shorter survival in gastric carcinoma (20). The variant has also been reported in colorectal cancer (21) and head and neck squamous cell carcinomas (HNSCC) (22). We found a significant increase in MVD in the GBM group but did not observe this effect in gliomas grade 2 and 3 . Hence, the Q472H variant was enriched in GBMs with increased MVD though it did not seem to affect vascular morphology. The mechanisms of $K D R$ variants in this context are not clear, however, it has recently been demonstrated in vitro $(50,51)$ that GBM cells can secrete factors to increase human brain endothelial cell migration. If $K D R \quad \mathrm{Q} 472 \mathrm{H}$ represents increased activity or sensitivity of the receptor, then this may explain the enhanced MVD in GBM patients who tested positive for $K D R \mathrm{Q} 472 \mathrm{H}$. To put this in to context, this elevated MVD reflects abnormal angiogenesis, which represents a growth advantage permitting the increased access to nutrients $(52)$ and tumour cell invasion $(53,54)$. Moreover, an association between this variant of $K D R$ and the risk of glioma has been described previously, hence this abnormal angiogenesis may be a factor involved in initial tumorigenesis as commented by the original study (55). It is reasonable to hypothesise that patients with more angiogenic tumours may have a worse survival rate (56), hence patients with the $\mathrm{Q} 472 \mathrm{H}$ variant may have poorer prognosis. We showed that GBM patients with $K D R \mathrm{Q} 472 \mathrm{H}$ have an overall shorter survival, and this may be related to increases in MVD. MGMT methylation does not influence survival in this case as we did not observe any clear correlations between $M G M T$ promoter methylation and $\mathrm{Q} 472 \mathrm{H}$ status.

However, increases in MVD have been shown to act as a double-edged sword in HNSCC (22), and similar effects may be observed in gliomas. Changes in MVD may influence the efficacy of radiotherapy as a result of changes in the 

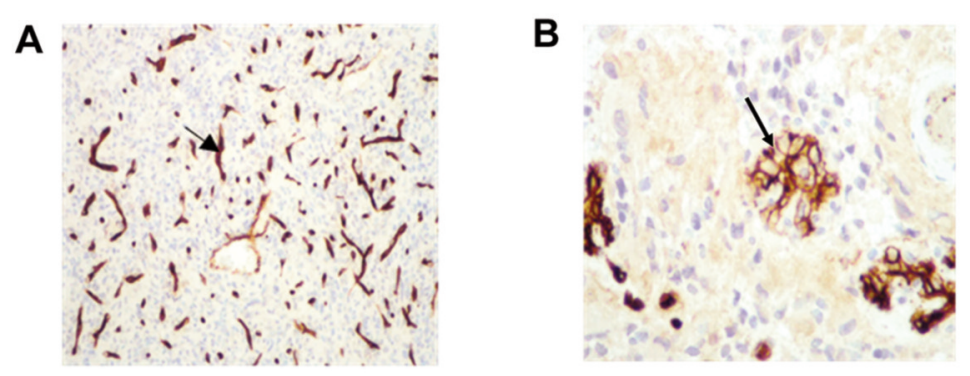

Low Grade Glioma

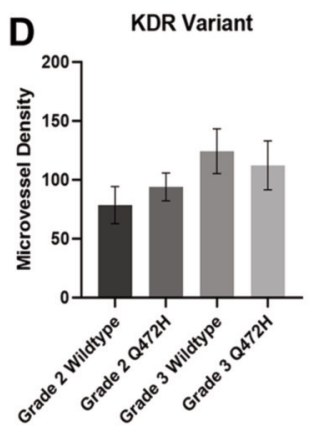

G

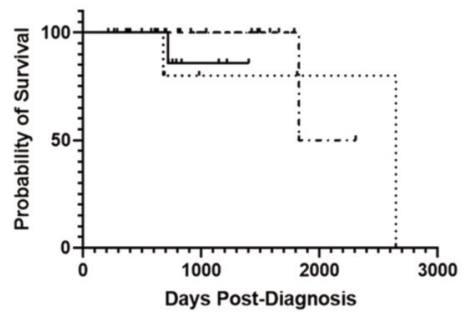

- Grade 2 Wildtype

-2. Grade 2 Q472H

... Grade 3 Wildtype

.. Grade 3 Q472H

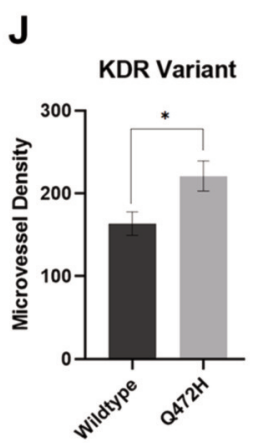

K

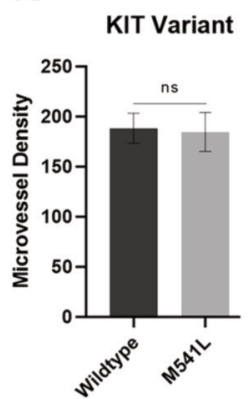

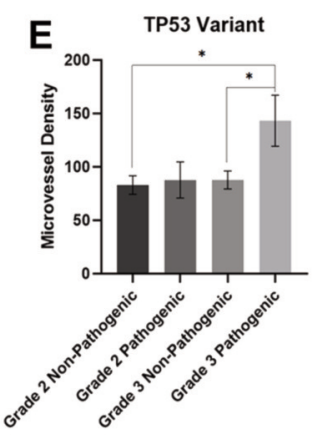

H

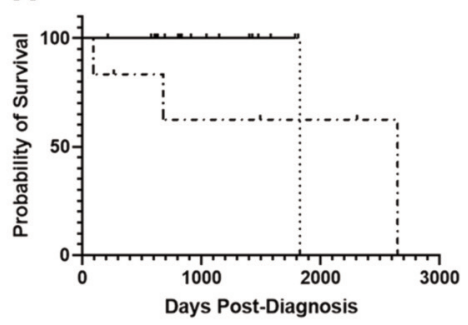

- Grade 2 Non-Pathogenic

... Grade 2 Pathogenic

.. Grade 3 Non-Pathogenic

.'- Grade 3 Pathogenic

\section{Glioblastoma}

\section{L}

\section{Mean Microvessel Density}

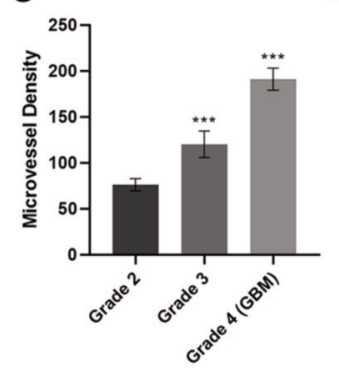

$\mathbf{F}$
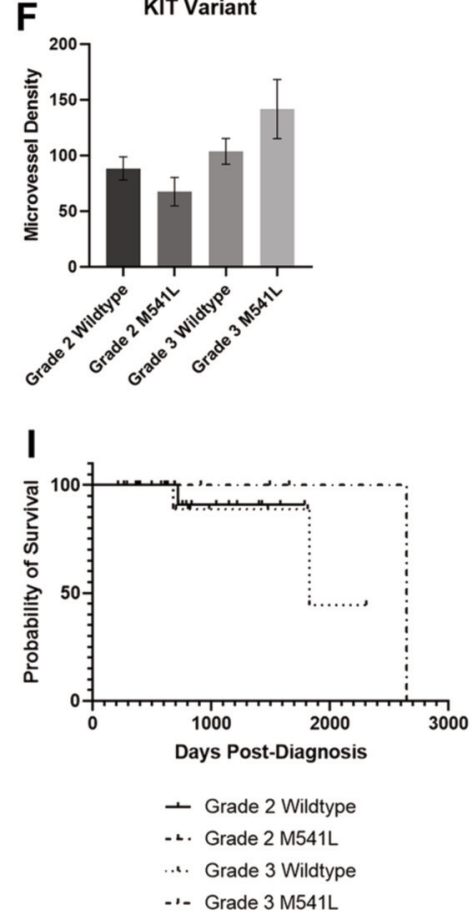

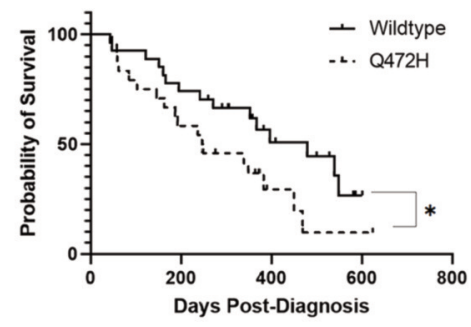

M

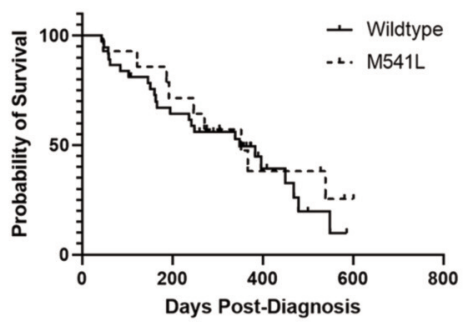

Figure 3. Microvessel density (MVD) and survival analysis. CD34 IHC of tissue sections of glioma biopsies to measure MVD; an example of classical (A) and bizarre (B) angiogenesis (20X magnification). (C) Mean MVD for grade 2 ( $n=21)$, grade 3 ( $n=16)$ and grade 4 ( $n=52)$ gliomas. Data shown are mean \pm SEM. $* * * p<0.001$, One-way ANOVA. Some data are excluded as outliers. Comparing MVD between grade 2-3 glioma patients with (D) WT and $Q 472 \mathrm{H}$ variants of KDR; $n=40, p=0.23$, (E) pathogenic and non-pathogenic variants of TP53; $n=28, * p<0.05,(F)$ WT and M541L variants of KIT; $n=41$, $p=0.088$. Kaplan-Meier survival curves of grade 2-3 patients with $(G)$ WT or Q472H variants of KDR; $n=40, p=0.73,(H)$ pathogenic and non-pathogenic variants of TP53; $n=28, p=0.46$, (I) WT and M541L variants of KIT; $n=41, p=0.79$. Comparing MVD density between glioblastoma (GBM) patients with (J) WT KDR and the $Q 472 H$ variant of KDR; $n=52, * p=0.015$, $(K)$ WT KIT and the M541L variant of KIT; $n=52$, $p=0.89$. Kaplan-Meier survival curves of GBM patients with $(L)$ WT or $Q 472 H$ variants of KDR; $n=52$, * $p=0.045,(M)$ WT or M541L variants of KIT; $n=52$, $p=0.52$. Grade 2-3 data analysed with one-way ANOVA. GBM data analysed with unpaired t-test. Survival curves analysed with Log-Rank test. Data shown for MVD are mean \pm SEM. 


\section{KIT Variant}

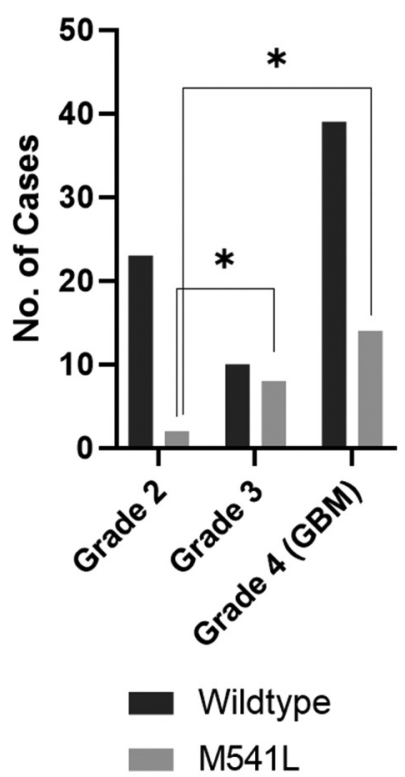

Figure 4. Number of cases positive for WT or M541L variants of KIT in grade $2(n=25)$, grade $3(n=18)$ and glioblastoma (GBM; $n=53)$. There is a significant increase in the number of cases positive for M541L as glioma grade increases. $X^{2}(2, N=96)=7.5396, * p<0.05$.

oxygenation of the tumour $(52,57)$. In fact, Tinhofer et al., (22) has demonstrated this by showing that KDR Q472Hpositive HNSCC patients had a significantly better survival when receiving chemo-radiation $v s$. KDR WT patients. Chemo-radiation is standard practice of the treatment of high-grade gliomas, hence identifying KDR Q472H patients may identify those who may benefit greater from these regimens, or from anti-angiogenic therapies $(14,58)$.

Interestingly, we also found that pathogenic TP53 variants enhance MVD only in grade 3 astrocytomas. WT TP53 is a known suppressor of angiogenesis $(44,59)$ and, therefore, pathogenic TP53 may enhance angiogenesis as we showed in our astrocytoma grade 3 cases, though in our cohort, this enhancement did not affect survival. TP53 mutations are common in IDH mut astrocytomas (60). It is, thus, possible that pathogenic TP53 primes IDH mut astrocytomas for high level MVD to contribute to progression to GBM.

Transcriptomic analysis (46) has identified an immunosuppressive phenotype in KDR Q472H tumours; subsequent blockade of $K D R$ augmented the anti-tumour immune response in a mouse melanoma model. This may be relevant to the increasing number of studies surrounding the use of immunotherapy in gliomas (61) and may, in the future, identify those patients who would benefit greater from immunotherapy strategies. Although we did not assess the inflammatory infiltration in this study, it could be important to examine whether $K D R \mathrm{Q} 472 \mathrm{H}$ is associated with a reduced inflammatory response in gliomas in the future.

Gain- and loss-of-function mutations in KIT have been implicated in numerous types of cancer (62) in tumour cell proliferation, including cancer stem cell proliferation (63), as well as endothelial proliferation in gliomas, supporting tumour-associated angiogenesis $(41,64)$. In our study, patients with KIT mutations carry M541L, a variant that has been shown to increase the affinity of the receptor to its ligand, stem cell factor (SCF) $(65,66)$. This effect on SCF binding should in theory increase the sensitivity to imatinib, yet there are conflicting reports of this observation in clinical settings $(67,68)$. In our study, we observed that the presence of KIT M541L does not significantly affect MVD in the context of gliomas. Interestingly we observed the majority of KIT M541L positive cases in grade 3 and 4 gliomas. This variant has been found in patients with gliomas (69), however, its significance is not known. It is possible that the KIT M514L mutation affects aggressiveness with a different mechanism that does not involve angiogenesis regulation. It is unknown whether KIT M541L could serve as a potential diagnostic marker of high-grade glioma or faster progression to higher grade for earlier intervention strategies, and this should be verified in a larger cohort of low-grade glioma patients.

We used artificial intelligence (AI) to search for further insights into the relationship between the mutation status of oncogenes in the panel and clinically relevant features. We decided to build an ANN to predict MGMT promoter methylation in GBM as it is used to plan treatment strategies. Temozolomide is the gold-standard therapy of gliomas (70) but its activity is circumvented through MGMT promoter methylation (71). We proposed the use of targeted NGS data fed into an AI model to predict MGMT methylation, and we achieved this with an $86 \%$ accuracy. The model is unable to

Figure 5. Deep learning model. This is built using the functional Keras API and TensorFlow 2.0 that can be used to predict MGMT promoter methylation status with $86 \%$ accuracy on test data (A). The model takes the sequencing information of GBM patients $(n=48)$ as input data and proceeds to predict whether the patient will have methylated MGMT. Data are augmented by rearranging the order of genes to increase sample size. (B) Loss between the training and test data converge at $86 \%$ prediction accuracy, suggesting that the model does not overfit by the end of training. ANN loses predictive capacity for methylation upon the removal of PIK3CA, KIT and KDR mutation status $(C)$. Accuracy is diminished to $72 \%$ upon the removal of PIK3CA $(D), K I T(E)$ or $K D R(F)$ individually and $K I T / K D R(H), P I K 3 C A / K D R(I)$ paired removal. Accuracy is further reduced to $57 \%$ upon removal of PIK3CA/KIT $(G)$. Loss of mutation information for PIK3CA, KIT and KDR results in model overfitting $(J)$, where test loss values are greater than training loss values. 

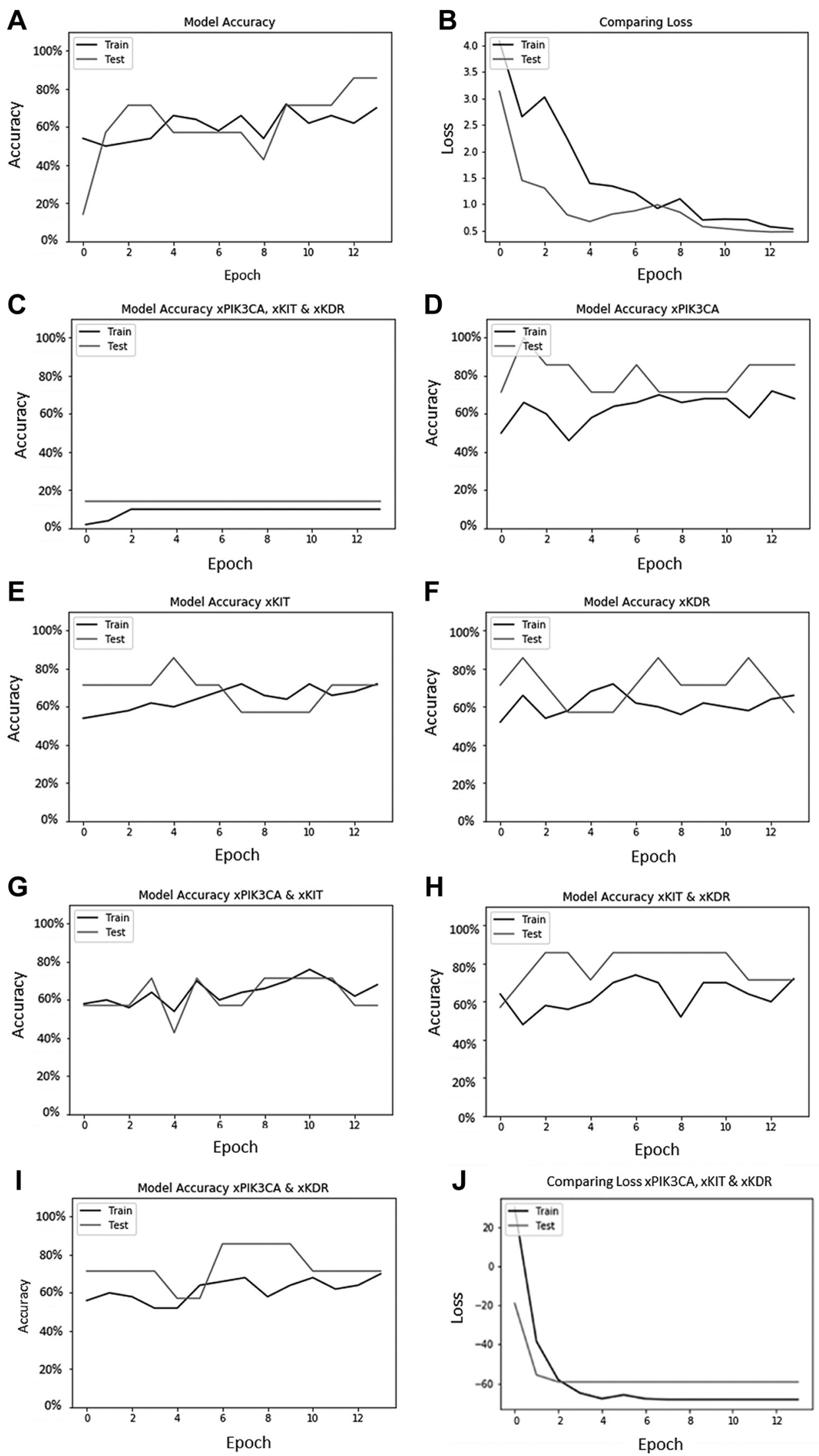
progress with further than $86 \%$ accuracy, but issues regarding accuracy could be resolved by providing a larger set of data to train the system on. Interestingly, in our model the variant status of $K I T, K D R$ and PIK3CA - a signal transduction component in the activation of KIT (42) and KDR (43), are necessary to predict $M G M T$ promoter methylation. Even though the link between angiogenesis-related genes and $M G M T$ promoter methylation is not clear, a similar association between $M G M T$ expression and decreased angiogenesis has been described experimentally in GBM, in vitro (72).

In conclusion, using NGS we identified the presence of $K D R \mathrm{Q} 472 \mathrm{H}$ in a large proportion of our glioma patient cohort and linked it to an increase in MVD and poorer survival. As a germline mutation, this variant may predispose individuals to more aggressive tumours. Based on this study we suggest that the $K D R \mathrm{Q} 472 \mathrm{H}$ status should also be included during reporting after these data have been verified in a larger study cohort. Reporting KDR Q472H status may identify patients who may incur greater benefits from more aggressive radiotherapy treatment regimens or from the inclusion of anti-angiogenic therapies and immunotherapy strategies. Our study also highlights the potential diagnostic significance of a KIT variant, to assess grade as well as monitor the grade change of astrocytomas. Our findings support the importance of incorporating germline variants into the genetic profile of neoplasms and extending it to the diagnosis of gliomas.

\section{Conflicts of Interest}

The Authors report no conflicts of interest.

\section{Authors' Contributions}

JK and CL designed and supervised the project. PDP, SM, LG, LT performed sequencing and contributed to sequencing data analysis. $\mathrm{NZ}$ and SSD conducted genotyping for the validation cohort. SSD and CL performed histological examination. NZ, SSD, JK and CL analyzed data. NZ constructed the AI model and wrote the manuscript. All Authors have read and approved the manuscript.

\section{Acknowledgements}

The Authors would like to thank the members of the molecular genetics laboratory at Hammersmith Hospital, Imperial College Healthcare NHS Trust for their technical assistance with this work.

\section{References}

1 Ostrom QT, Cioffi G, Gittleman H, Patil N, Waite K, Kruchko $\mathrm{C}$ and Barnholtz-Sloan JS: CBTRUS Statistical Report: Primary brain and other central nervous system tumors diagnosed in the United States in 2012-2016. Neuro Oncol 21(Suppl 5): v1-v100, 2019. PMID: 31675094. DOI: 10.1093/neuonc/noz150
2 Louis D, Perry A, Reifenberger G, von Deimling A, FigarellaBranger D, Cavenee W, Ohgaki H, Wiestler O, Kleihues P and Ellison D: The 2016 World Health Organization Classification of Tumors of the Central Nervous System: a summary. Acta Neuropathol 131(6): 803-820, 2016. PMID: 27157931. DOI: 10.1007/s00401-016-1545-1

3 Brat D, Aldape K, Colman H, Holland E, Louis D, Jenkins R, Kleinschmidt-DeMasters B, Perry A, Reifenberger G, Stupp R, von Deimling A and Weller M: cIMPACT-NOW update 3: recommended diagnostic criteria for "Diffuse astrocytic glioma, IDH-wildtype, with molecular features of glioblastoma, WHO grade IV". Acta Neuropathol 136(5): 805-810, 2018. PMID: 30259105. DOI: $10.1007 / \mathrm{s} 00401-018-1913-0$

4 Sarkaria JN, Kitange GJ, James CD, Plummer R, Calvert H, Weller $\mathrm{M}$ and Wick W: Mechanisms of chemoresistance to alkylating agents in malignant glioma. Clin Cancer Res 14(10): 2900-2908, 2008. PMID: 18483356. DOI: 10.1016/j.molcel.2007.05.041.A

5 Da Ros M, Gregorio V, Iorio AL, Giunti L, Guidi M, Martino M, Genitori L and Sardi I: Glioblastoma chemoresistance: The double play by microenvironment and blood-brain barrier. Int J Mol Sci 19(10): 2879, 2018. PMID: 30248992. DOI: 10.3390/ijms 19102879

6 Naidu MD, Mason JM, Pica RV, Fung H and Pe Na LA: Radiation resistance in glioma cells determined by DNA damage repair activity of Ape1/Ref-1. J Radiat Res 51(4): 393-404, 2010. PMID: 20679741. DOI: 10.1269/jrr.09077

7 Tamimi AF and Juweid M: Epidemiology and outcome of glioblastoma. Glioblastoma Chapter 8: 143-153, 2017. PMID: 29251870. DOI: $10.15586 /$ codon.glioblastoma.2017.ch8

8 Huang RY, Neagu MR, Reardon DA and Wen PY: Pitfalls in the neuroimaging of glioblastoma in the era of antiangiogenic and immuno/ targeted therapy - detecting illusive disease, defining response. Front Neurol 6: 33, 2015. PMID: 25755649. DOI: 10.3389/fneur.2015.00033

9 Lieberman F: Glioblastoma update: Molecular biology, diagnosis, treatment, response assessment, and translational clinical trials. F1000Res 6: 1892, 2017. PMID: 29263783. DOI: 10.12688/f1000research.11493.1

10 Park S, Won J, Kim S, Lee Y, Park C, Kim S and Choi S: Molecular testing of brain tumor. J Pathol Transl Med 51(3): 205223, 2017. PMID: 28535583. DOI: 10.4132/jptm.2017.03.08

11 Das S and Marsden PA: Angiogenesis in glioblastoma. N Engl J Med 369(16): 1561-1563, 2013. PMID: 24131182. DOI: 10.1056/NEJMcibr1309402

12 Onishi M, Kurozumi K, Ichikawa T and Date I: Mechanisms of tumor development and anti-angiogenic therapy in glioblastoma multiforme. Neurol Med Chir 53(11): 755-763, 2013. PMID: 24162241. DOI: $10.2176 /$ nmc.ra2013-0200

13 Kaur B, Khwaja FW, Severson EA, Matheny SL, Brat DJ and Van Meir Erwin G: Hypoxia and the hypoxia-inducible-factor pathway in glioma growth and angiogenesis. Neuro Oncol 7(2): 134-153, 2005. PMID: 15831232. DOI: 10.1215/S1152851704001115

14 Ahir BK, Engelhard HH and Lakka SS: Tumor development and angiogenesis in adult brain tumor: Glioblastoma. Molecular Neurobiol 57(5): 2461-2478, 2020. PMID: 32152825. DOI: 10.1007/s12035-020-01892-8

15 Johannessen LE, Brandal P, Myklebust TÅ, Heim S, Micci F and Panagopoulos I: MGMT gene promoter methylation status assessment of two pyrosequencing kits and three methylationspecific PCR methods for their predictive capacity in 
glioblastomas. Cancer Genomics Proteomics 15(6): 437-446, 2018. PMID: 30343277. DOI: $10.21873 /$ cgp.20102

16 Synhaeve NE, van den Bent, Martin J., French PJ, Dinjens WNM, Atmodimedjo PN, Kros JM, Verdijk R, Dirven CMF and Dubbink HJ: Clinical evaluation of a dedicated next generation sequencing panel for routine glioma diagnostics. Acta Neuropathol Commun 6(1): 126, 2018. PMID: 30470264. DOI: $10.1186 / \mathrm{s} 40478-018-$ 0633-y

17 Parilla M, Kadri S, Patil SA, Fitzpatrick C, Ritterhouse L, Segal $\mathrm{J}$, Collins $\mathrm{J}$ and Pytel P: Integrating a large next-generation sequencing panel into the clinical diagnosis of gliomas provides a comprehensive platform for classification from FFPE tissue or smear preparations. J Neuropathol Exp Neurol 78(3): 257-267, 2019. PMID: 30698790. DOI: 10.1093/jnen/nly130

18 Silva IP, Salhi A, Giles KM, Vogelsang M, Han SW, Ismaili N, Lui KP, Robinson EM, Wilson MA, Shapiro RL, Pavlick A, Zhong J, Kirchhoff $\mathrm{T}$ and Osman I: Identification of a novel pathogenic germline KDR variant in melanoma. Clin Cancer Res 22(10): 23772385, 2016. PMID: 26631613. DOI: 10.1158/1078-0432.CCR-151811

19 Glubb DM, Cerri E, Giese A, Zhang W, Mirza O, Thompson EE, Chen P, Das S, Jassem J, Rzyman W, Lingen MW, Salgia R, Hirsch FR, Dziadziuszko R, Ballmer-Hofer K and Innocenti F: Novel functional germline variants in the VEGF receptor 2 gene and their effect on gene expression and microvessel density in lung cancer. Clin Cancer Res 17(16): 5257-5267, 2011. PMID: 21712447. DOI: 10.1158/1078-0432.CCR-11-0379

20 Zhu X, Wang Y, Xue W, Wang R, Wang L, Zhu M and Zheng L: The VEGFR-2 protein and the VEGFR-2 rs1870377 A>T genetic polymorphism are prognostic factors for gastric cancer. Cancer Biol Ther 20(4): 497-504, 2019. PMID: 30380970. DOI: 10.1080/15384047.2018.1537575

21 Jauhri M, Gupta V, Shokeen Y, Minhas S, Bhalla S and Aggarwal S: KDR Mutation: A high-frequency rare mutation and its correlation with other somatic mutations in Indian colorectal cancer patients. Next Generat Sequenc \& Applic 4(2): 148, 2017. DOI: $10.4172 / 2469-9853.1000148$

22 Tinhofer I, Stenzinger A, Eder T, Konschak R, Niehr F, Endris V, Distel L, Hautmann MG, Mandic R, Stromberger C, Weichert $\mathrm{W}$ and Budach V: Targeted next-generation sequencing identifies molecular subgroups in squamous cell carcinoma of the head and neck with distinct outcome after concurrent chemoradiation. Ann Oncol 27(12): 2262-2268, 2016. PMID: 27681865. DOI: $10.1093 /$ annonc/mdw426

23 Christians A, Adel-Horowski A, Banan R, Lehmann U, Bartels S, Behling F, Barrantes-Freer A, Stadelmann C, Rohde V, Stockhammer F and Hartmann C: The prognostic role of IDH mutations in homogeneously treated patients with anaplastic astrocytomas and glioblastomas. Acta Neuropathol Commun 7: 156, 2019. PMID: 31623667. DOI: 10.1186/s40478-019-0817-0

24 Tate JG, Bamford S, Jubb HC, Sondka Z, Beare DM, Bindal N, Boutselakis H, Cole CG, Creatore C, Dawson E, Fish P, Harsha B, Hathaway C, Jupe SC, Kok CY, Noble K, Ponting L, Ramshaw CC, Rye CE, Speedy HE, Stefancsik R, Thompson SL, Wang S, Ward S, Campbell PJ and Forbes SA: COSMIC: the Catalogue Of Somatic Mutations In Cancer. Nucleic Acids Res 47(D1): D941-D947, 2019. PMID: 30371878. DOI: 10.1093/nar/gky1015

25 Adzhubei IA, Schmidt S, Peshkin L, Ramensky VE, Gerasimova A, Bork P, Kondrashov AS and Sunyaev SR: A method and server for predicting damaging missense mutations. Nat Methods 7(4): 248-249, 2010. PMID: 20354512. DOI: 10.1038/nmeth0410-248

26 Patterson SE, Liu R, Statz CM, Durkin D, Lakshminarayana A and Mockus SM: The clinical trial landscape in oncology and connectivity of somatic mutational profiles to targeted therapies. Hum Genomics 10: 4, 2016. PMID: 26772741. DOI: 10.1186/s40246-016-0061-7

27 Chakravarty D, Gao J, Phillips S, Kundra R, Zhang H, Wang J, Rudolph JE, Yaeger R, Soumerai T, Nissan MH, Chang MT, Chandarlapaty S, Traina TA, Paik PK, Ho AL, Hantash FM, Grupe A, Baxi SS, Callahan MK, Snyder A, Chi P, Danila DC, Gounder M, Harding JJ, Hellmann MD, Iyer G, Janjigian YY, Kaley T, Levine DA, Lowery M, Omuro A, Postow MA, Rathkopf D, Shoushtari AN, Shukla N, Voss MH, Paraiso E, Zehir A, Berger MF, Taylor BS, Saltz LB, Riely GJ, Ladanyi M, Hyman DM, Baselga J, Sabbatini P, Solit DB and Schultz N: OncoKB: A precision oncology knowledge base. JCO Precis Oncol 2017: 116, 2017. PMID: 28890946. DOI: 10.1200/po.17.00011

28 Gentleman R, Carey V, Bates D, Bolstad B, Dettling M, Dudoit S, Ellis B, Gautier L, Ge Y, Gentry J, Hornik K, Hothorn T, Huber W, Iacus S, Irizarry R, Leisch F, Li C, Maechler M, Rossini A, Sawitzki G, Smith C, Smyth G, Tierney L, Yang J and Zhang J: Bioconductor: open software development for computational biology and bioinformatics. Genome Biol 5(10): R80, 2004. PMID: 15461798. DOI: 10.1186/gb-2004-5-10-r80

29 Lê S, Josse J and Husson F: FactoMineR: An R package for multivariate analysis. J Stat Softw 25(1): 1-18, 2008. DOI: 10.18637/jss.v025.i01

30 Abadi M, Agarwal A, Barham P, Brevdo E, Chen Z, Citro C, Corrado GS, Davis A, Dean J, Devin M, Ghemawat S, Goodfellow I, Harp A, Irving G, Isard M, Jia Y, Jozefowicz R, Kaiser L, Kudlur M, Levenberg J, Mane D, Monga R, Moore S, Murray D, Olah C, Schuster M, Shlens J, Steiner B, Sutskever I, Talwar K, Tucker P, Vanhoucke V, Vasudevan V, Viegas F, Vinyals $O$, Warden $P$, Wattenberg M, Wicke M, Yu Y and Zheng X: TensorFlow: Largescale machine learning on heterogeneous distributed systems, 2016. Software available at: https://www.tensorflow.org

31 Chollet F and others: Keras. Available at: https://github.com/ fchollet/keras

32 Vermeulen PB, Gasparini G, Fox SB, Toi M, Martin L, McCulloch P, Pezzella F, Viale G, Weidner N, Harris AL and Dirix LY: Quantification of angiogenesis in solid human tumours: An international consensus on the methodology and criteria of evaluation. Eur J Cancer 32A(14): 2474-2484, 1996. PMID: 9059336. DOI: 10.1016/s0959-8049(96)00379-6

33 Birner P, Piribauer M, Fischer I, Gatterbauer B, Marosi C, Ambros PF, Ambros IM, Bredel M, Oberhuber G, Rössler K, Budka H, Harris AL and Hainfellner JA: Vascular patterns in glioblastoma influence clinical outcome and associate with variable expression of angiogenic proteins: evidence for distinct angiogenic subtypes. Brain Pathol 13(2): 133-143, 2003. PMID: 12744467. DOI: 10.1111/j.1750-3639.2003.tb00013.x.

34 Stratton MR, Campbell PJ and Futreal PA: The cancer genome. Nature 458(7239): 719-724, 2009. PMID: 19360079. DOI: 10.1038 /nature 07943

35 Aggarwal CC, Hinneburg A and Keim DA: On the Surprising Behavior of Distance Metrics in High Dimensional Space In: Van den Bussche J, Vianu V (eds) Database Theory - ICDT 2001. ICDT 2001. Lecture Notes in Computer Science vol 1973, 2001. DOI: $10.1007 / 3-540-44503-x \_27$ 
36 Pang RWC and Poon RTP: Clinical implications of angiogenesis in cancers. Vasc Health Risk Manag 2(2): 97-108, 2006. PMID: 17319453. DOI: $10.2147 / \mathrm{vhrm} .2006 .2 .2 .97$

37 Wang Z, Dabrosin C, Yin X, Fuster MM, Arreola A, Rathmell WK, Generali D, Nagaraju GP, El-Rayes B, Ribatti D, Chen YC, Honoki K, Fujii H, Georgakilas AG, Nowsheen S, Amedei A, Niccolai E, Amin A, Ashraf SS, Helferich B, Yang X, Guha G, Bhakta D, Ciriolo MR, Aquilano K, Chen S, Halicka D, Mohammed SI, Azmi AS, Bilsland A, Keith WN and Jensen LD: Broad targeting of angiogenesis for cancer prevention and therapy. Semin Cancer Biol 35(Suppl): S224-S243, 2015. PMID: 25600295. DOI: 10.1016/j.semcancer.2015.01.001

38 Teleanu RI, Chircov C, Grumezescu AM and Teleanu DM: Tumor angiogenesis and anti-angiogenic strategies for cancer treatment. J Clin Med 9(1): 84, 2019. PMID: 31905724. DOI: $10.3390 / \mathrm{jcm} 9010084$

39 Jain RK, Sorensen AG, Duda DG, Batchelor TT, Loeffler JS and di Tomaso E: Angiogenesis in brain tumours. Nat Rev Neurosci 8(8): 610-622, 2007. PMID: 17643088. DOI: 10.1038/nrn2175

40 Bulnes S, Bilbao J and Lafuente JV: Microvascular adaptive changes in experimental endogenous brain gliomas. Histol Histopathol 24(6): 693-706, 2009. PMID: 19337968. DOI: $10.14670 / \mathrm{HH}-24.693$

41 Sun L, Hui A, Su Q, Vortmeyer A, Kotliarov Y, Pastorino S, Passaniti A, Menon J, Walling J, Bailey R, Rosenblum M, Mikkelsen T and Fine HA: Neuronal and glioma-derived stem cell factor induces angiogenesis within the brain. Cancer Cell 9(4): 287-300, 2006. PMID: 16616334 DOI: 10.1016/j.ccr.2006.03.003

42 Bosbach B, Rossi F, Yozgat Y, Loo J, Zhang JQ, Berrozpe G, Warpinski K, Ehlers I, Veach D, Kwok A, Manova K, Antonescu CR, DeMatteo RP and Besmer P: Direct engagement of the PI3K pathway by mutant KIT dominates oncogenic signaling in gastrointestinal stromal tumor. Proc Natl Acad Sci USA 114(40): E8448-E8457, 2017. PMID: 28923937. DOI: 10.1073/pnas.171 1449114

43 Jiang B and Liu L: PI3K/PTEN signaling in angiogenesis and tumorigenesis. Adv Cancer Res 102: 19-65, 2009. PMID: 19595306. DOI: 10.1016/S0065-230X(09)02002-8

44 Song R, Tian K, Wang W and Wang L: P53 suppresses cell proliferation, metastasis, and angiogenesis of osteosarcoma through inhibition of the PI3K/AKT/mTOR pathway. Int J Surg 20: 80-87, 2015. PMID: 25936826. DOI: 10.1016/j.ijsu.2015.04.050

45 Feng ZC, Popell A, Li J, Silverstein J, Oakie A, Yee SP and Wang R: C-Kit receptor signaling regulates islet vasculature, $\beta$ cell survival, and function in vivo. Diabetes 64(11): 3852-3866, 2015. PMID: 26253609. DOI: $10.2337 / \mathrm{db} 15-0054$

46 Chou M, Giles KM, Illa-Bochaca I, Mastroianni J, de Miera E, Krogsgaard $\mathrm{M}$ and Osman I: Association of pathogenic germline variant KDR Q472H with angiogenesis and resistance to treatment in melanoma. J Clin Oncol 38(15 Suppl): 10060, 2020. DOI: $10.1200 / J C O .2020 .38 .15 \_s u p p l .10060$

47 Yates AD, Achuthan P, Akanni W, Allen J, Allen J, Alvarez-Jarreta J, Amode MR, Armean IM, Azov AG, Bennett R, Bhai J, Billis K, Boddu S, Marugán JC, Cummins C, Davidson C, Dodiya K, Fatima R, Gall A, Giron CG, Gil L, Grego T, Haggerty L, Haskell E, Hourlier T, Izuogu OG, Janacek SH, Juettemann T, Kay M, Lavidas I, Le T, Lemos D, Martinez JG, Maurel T, McDowall M, McMahon A, Mohanan S, Moore B, Nuhn M, Oheh DN, Parker A, Parton A, Patricio M, Sakthivel MP, Abdul Salam AI, Schmitt BM, Schuilenburg H, Sheppard D, Sycheva M, Szuba M, Taylor
K, Thormann A, Threadgold G, Vullo A, Walts B, Winterbottom A, Zadissa A, Chakiachvili M, Flint B, Frankish A, Hunt SE, IIsley G, Kostadima M, Langridge N, Loveland JE, Martin FJ, Morales J, Mudge JM, Muffato M, Perry E, Ruffier M, Trevanion SJ, Cunningham F, Howe KL, Zerbino DR and Flicek P: Ensembl 2020. Nucleic Acids Res 48(D1): D682-D688, 2020. PMID: 31691826. DOI: $10.1093 /$ nar/gkz966

48 Roskoski R: Vascular endothelial growth factor (VEGF) signaling in tumor progression. Crit Rev Oncol Hematol 62(3): 179-213, 2007. PMID: 17324579. DOI: 10.1016/j.critrevonc.2007.01.006

49 Simons M, Gordon E and Claesson-Welsh L: Mechanisms and regulation of endothelial VEGF receptor signalling. Nat Rev Mol Cell Biol 17(10): 611-625, 2016. PMID: 27461391. DOI: $10.1038 / \mathrm{nrm} .2016 .87$

50 DE Oliveira Rosario, Luciane Vieira, DA Rosa BG, Goncalves TL, Matias DIL, Freitas C and Ferrer VP: Glioblastoma factors increase the migration of human brain endothelial cells in vitro by increasing MMP-9/CXCR4 levels. Anticancer Res 40(5): 27252737, 2020. PMID: 32366418. DOI: 10.21873/anticanres.14244

51 Liang W, Guo B, Ye J, Liu H, Deng W, Lin C, Zhong X and Wang L: Vasorin stimulates malignant progression and angiogenesis in glioma. Cancer Sci 110(8): 2558-2572, 2019. PMID: 31215106 . DOI: $10.1111 /$ cas.14103

52 Folkman J: Role of angiogenesis in tumor growth and metastasis. Semin Oncol 29(6 Suppl 16): 15-18, 2002. PMID: 12516034. DOI: 10.1053 /sonc.2002.37263

53 Tate MC and Aghi MK: Biology of angiogenesis and invasion in glioma. Neurotherapeutics 6(3): 447-457, 2009. PMID: 19560735. DOI: 10.1016/j.nurt.2009.04.001

54 Onishi M, Ichikawa T, Kurozumi K, and Date I: Angiogenesis and invasion in glioma. Brain Tumor Pathol 28(1): 13-24, 2011. PMID: 21221826. DOI: 10.1007/s10014-010-0007-Z

55 Zhang J, Yang J, Chen Y, Mao Q, Li S, Xiong W, Lin Y, Chen J and Ge J: Genetic variants of VEGF (rs201963 and rs3025039) and KDR (rs7667298, rs2305948, and rs 1870377) are associated with glioma risk in a han chinese population: a case-control study. Mol Neurobiol 53(4): 2610-2618, 2016. PMID: 26093379. DOI: $10.1007 / \mathrm{s} 12035-015-9240-0$

56 Leon SP, Folkerth RD and Black PM: Microvessel density is a prognostic indicator for patients with astroglial brain tumors. Cancer 77(2): 362-372, 1996. PMID: 8625246. DOI: $10.1002 /($ SICI) 1097-0142(19960115)77:2<362::AIDCNCR20>3.0.CO;2-Z

57 Graham K and Unger E: Overcoming tumor hypoxia as a barrier to radiotherapy, chemotherapy and immunotherapy in cancer treatment. Int J Nanomedicine 13, 2018. PMID: 30323592. DOI: 10.2147/IJN.S140462

58 Plate K, Scholz A and Dumont D: Tumor angiogenesis and antiangiogenic therapy in malignant gliomas revisited. Acta Neuropathol 124(6): 763-775, 2012. PMID: 23143192. DOI: 10.1007/s00401-012-1066-5

59 Zhang L, Yu D, Hu M, Xiong S, Lang A, Ellis LM and Pollock RE: Wild-type p53 suppresses angiogenesis in human leiomyosarcoma and synovial sarcoma by transcriptional suppression of vascular endothelial growth factor expression. Cancer Res 60(13): 3655-3661, 2000. PMID: 10910082.

60 The Cancer Genome Atlas Research Network: Comprehensive, integrative genomic analysis of diffuse lower-grade gliomas. N Engl J Med 372(26): 2481-2498, 2015. PMID: 26061751. DOI: 10.1056/NEJMoa1402121 
61 McGranahan T, Therkelsen KE, Ahmad S and Nagpal S: Current State of Immunotherapy for Treatment of Glioblastoma. Curr Treat Options Oncol 20(3): 24, 2019. PMID: 30790064. DOI: 10.1007/s11864-019-0619-4

62 Abbaspour Babaei M, Kamalidehghan B, Saleem M, Huri HZ and Ahmadipour F: Receptor tyrosine kinase (c-Kit) inhibitors: a potential therapeutic target in cancer cells. Drug Des Devel Ther 10: 2443-2459, 2016. PMID: 27536065. DOI: 10.2147/DDDT. S89114

63 Pittoni P, Piconese S, Tripodo C and Colombo MP: Tumorintrinsic and -extrinsic roles of c-Kit: mast cells as the primary off-target of tyrosine kinase inhibitors. Oncogene 30(7): 757769, 2011. PMID: 21057534. DOI: 10.1038/onc.2010.494

64 Gomes AL, Reis-Filho JS, Lopes JM, Martinho O, Lambros MB, Martins A, Pardal F and Reis RM: Molecular alterations of KIT oncogene in gliomas. Cell Oncol 29(5): 399-408, 2007. PMID: 17726262. DOI: 10.1155/2007/926274

65 Foster R, Byrnes E, Meldrum C, Griffith R, Ross G, Upjohn E, Braue A, Scott R, Varigos G, Ferrao P and Ashman LK: Association of paediatric mastocytosis with a polymorphism resulting in an amino acid substitution (M541L) in the transmembrane domain of c-KIT. Br J Dermatol 159(5): 1160-1169, 2008. PMID: 18795925. DOI: $10.1111 /$ j.1365-2133.2008.08827.x

66 Chatterjee A, Ghosh J and Kapur R: Mastocytosis- a mutated KIT receptor induced myeloproliferative disorder. Oncotarget 6(21): 18250-18264, 2015. PMID: 26158763. DOI: 10.18632 /oncotarget.4213

67 Dufresne A, Alberti L, Brahmi M, Kabani S, Philippon H'i, P 'erol D and Blay JY: Impact of KIT exon 10 M541L allelic variant on the response to imatinib in aggressive fibromatosis: Analysis of the desminib series by competitive allele specific taqman PCR technology. BMC Cancer 14: 632, 2014. PMID: 25174682. DOI: $10.1186 / 1471-2407-14-632$
68 Iurlo A, Gianelli U, Beghini A, Spinelli O, Orofino N, Lazzaroni F, Cambiaghi S, Intermesoli T, Rambaldi A and Cortelezzi A: Identification of kitM5411 somatic mutation in chronic eosinophilic leukemia, not otherwise specified and its implication in low-dose imatinib response. Oncotarget 5(13): 4665-4670, 2014. PMID: 25015329. DOI: $10.18632 /$ oncotarget.1941

69 Saini M, Jha AN, Abrari A and Ali S: A subset of human gliomas shows over-expression of KIT without its amplification. Gene 497(2): 155-163, 2012. PMID: 22330882. DOI: 10.1016/j.gene. 2012.01.065

70 Paolillo M, Boselli C and Schinelli S: Glioblastoma under siege: An overview of current therapeutic strategies. Brain Sci 8(1): 15, 2018. PMID: 29337870. DOI: 10.3390/brainsci8010015

71 Lee SY: Temozolomide resistance in glioblastoma multiforme. Genes Dis 3(3): 198-210, 2016. PMID: 30258889. DOI: 10.1016/j.gendis.2016.04.007

72 Chahal M, Xu Y, Lesniak D, Graham K, Famulski K, Christensen JG, Aghi M, Jacques A, Murray D, Sabri S and Abdulkarim B: MGMT modulates glioblastoma angiogenesis and response to the tyrosine kinase inhibitor sunitinib. Neuro Oncol 12(8): 822-833, 2010. PMID: 20179017. DOI: 10.1093/ neuonc/noq017
Received August 24, 2020

Revised September 17, 2020

Accepted September 21, 2020 